\title{
PRODUTIVIDADE DE ALHO VERNALIZADO EM FUNÇÃO DE DOSES DE NITROGÊNIO E MOLIBDÊNIO $\left({ }^{1}\right)$
}

\author{
FÁBIO SILVA MACÊDO $\left({ }^{2 *}\right)$; ROVILSON JOSÉ DE SOUZA $\left({ }^{3}\right)$; JANICE GUEDES DE CARVALHO $\left({ }^{3}\right)$; \\ BRUNO RIBEIRO SANTOS $\left({ }^{3}\right)$; LEANDRA VICENTINA DOS REIS LEITE $\left({ }^{3}\right)$
}

\begin{abstract}
RESUMO
A introdução de cultivares nobres de alho originárias do Sul do país e da Argentina em novas regiões de cultivo, principalmente devido à adoção da técnica de vernalização, contribuiu significativamente para a elevação da produtividade e da qualidade do alho produzido no Brasil. Entretanto, poucos são os estudos visando determinar as exigências nutricionais de alho vernalizado. O nitrogênio exerce grande influência na elevação da produtividade e qualidade do alho, estando o molibdênio diretamente ligado à sua assimilação e aproveitamento. $\mathrm{O}$ objetivo deste trabalho foi avaliar a influência de doses de nitrogênio aplicadas em adubação de cobertura e doses de molibdênio via foliar na produtividade de alho vernalizado proveniente de cultura de meristemas. O experimento foi instalado sob delineamento de blocos casualizados, em esquema fatorial $5 \times 4$, sendo cinco doses de nitrogênio $\left(60,90,120,150\right.$ e $\left.180 \mathrm{~kg} \mathrm{ha}^{-1}\right)$ e quatro doses de molibdênio $(0,100,200$ e $300 \mathrm{~g}$ $\left.\mathrm{ha}^{-1}\right)$. O experimento foi desenvolvido em condições de campo, com três repetições. Os bulbos-semente da cultivar Roxo Pérola de Caçador provenientes de cultura de meristemas (4. ${ }^{a}$ multiplicação em campo) foram submetidos à vernalização por 50 dias a $4{ }^{\circ} \mathrm{C}$. A produtividade total e a comercial aumentaram de forma linear com o incremento na dose de nitrogênio aplicada em cobertura, não havendo diferenças significativas entre os tratamentos com relação à porcentagem de superbrotamento. Não se obteve resposta à aplicação de molibdênio nas doses avaliadas, sendo algumas características produtivas prejudicadas pela aplicação deste micronutriente.
\end{abstract}

Palavras-chave: Allium sativum, nutrição mineral, micronutrientes.

\section{ABSTRACT \\ PRODUCTIVITY OF VERNALIZED GARLIC IN FUNCTION OF NITROGEN AND MOLYBDENUM DOSES}

\begin{abstract}
The introduction of noble garlic cultivars from South of the Brazil and Argentina in new regions, mostly due to the vernalization technique, contributed significantly for elevation in the productivity and quality of the garlic produced in Brazil. However, few are the studies aiming determine the nutritional requirements of vernalized garlic. The nitrogen present high influence in the elevation of the productivity and quality in garlic, being the molybdenum directly related to the assimilation and utilization this nutrient. The objective of this work was to evaluate the influence of different topdressing nitrogen doses and molybdenum doses applied by foliar dressing in the productivity of vernalized garlic originated from tissue culture. The experiment was installed under the experimental design of randomized blocks, in factorial scheme $5 \times 4$, being five doses of nitrogen $\left(60,90,120,150\right.$, and $\left.180 \mathrm{~kg} \mathrm{ha}^{-1}\right)$ and four doses of molybdenum $\left(0,100,200\right.$ and $\left.300 \mathrm{~g} \mathrm{ha}^{-1}\right)$. The experiment was conducted under field conditions, with three replications. The bulbs of the cultivar Roxo Pérola de Caçador originated from tissue culture (four multiplications in field) used for planting were submitted to the vernalization by 50 days at $4^{\circ} \mathrm{C}$. The total and commercial productivities increased linearly with the topdressing nitrogen doses. No significant differences between the treatments were observed in relation to the index of secondary bulb growth. No response to the application of molybdenum doses by foliar dressing were verified, being some characteristics productive prejudiced with the application of this micronutrient.
\end{abstract}

Key words: Allium sativum, mineral nutrition, micronutrients.

$\left({ }^{1}\right)$ Recebido para publicação em $1 .^{\circ}$ de abril de 2008 e aceito em 20 de março de 2009. Parte de tese apresentada pelo primeiro autor ao Programa de Pós-Graduação em Agronomia/Fitotecnia da Universidade Federal de Lavras (UFLA).

( $\left.{ }^{2}\right)$ Empresa Brasileira de Pesquisa Agropecuária (EMBRAPA), Assessoria de Inovação Tecnológica (AIT), Parque Estação Biológica - PqEB, Av. W3 Norte (final), Ed. Sede, Caixa Postal 040315, 70770-901 Brasília (DF). E-mail: fabio.macedo@embrapa.br. $\left(^{*}\right)$ Autor correspondente.

$\left.{ }^{3}\right)$ Universidade Federal de Lavras (UFLA), Caixa Postal 3037, 37200-000 Lavras (MG). E-mail: rovilson@ufla.br; brunoagro2004@yahoo.com.br; leandraqconst@yahoo.com.br; janicegc@ufla.br 


\section{INTRODUÇÃO}

Os Estados de Minas Gerais, do Rio Grande do Sul, de Santa Catarina, Goiás e da Bahia são responsivos por $90 \%$ da produção brasileira de alho. Em 2003, Minas Gerais e Goiás tornaram-se os maiores produtores de alho do Brasil, com produtividades médias acima de $10 \mathrm{t} \mathrm{ha}^{-1}$. Este sucesso ocorreu em função de diversos fatores como o uso da mecanização, racionalização da irrigação, adensamento de plantio, uso de cultivares de alho nobre, vernalização e uso de alho livre de vírus (RESENDE et al., 2004).

As cultivares nobres são as mais exigentes em fotoperíodo (mínimo de 13 horas) e em frio, produzindo bulbos no extremo sul do país. Somente podem ser plantadas no centro-sul aplicando-se a vernalização, que altera as exigências agroclimáticas e reduz o ciclo. Esta técnica consiste em armazenar os bulbos inteiros em câmaras frias com $3{ }^{\circ} \mathrm{C}$ a $4{ }^{\circ} \mathrm{C}$ e umidade relativa de $70 \%$ a $80 \%$ por um período que varia de 40 a 55 dias (Filgueira, 2003). Contudo, RESENDE et al. (2004) ressaltam que, para cultivares de alho nobre submetidas à vernalização, deve-se atentar para o manejo adequado da irrigação e da adubação nitrogenada, principais fatores relacionados à incidência de superbrotamento.

O superbrotamento ou pseudobulbificação é uma anomalia genético-fisiológica, que se caracteriza pela formação de pseudobulbos em cultivares que requerem a vernalização. Os brotos novos crescem através do pseudocaule e emergem nas axilas das folhas, dando à planta o aspecto de uma ramificação abundante. É uma característica que influi negativamente na cultura do alho, pois, além de reduzir a produtividade, deprecia o produto, fazendo com que seu valor comercial seja comprometido (SouzA e CASALI, 1986).

O nitrogênio é absorvido em grande quantidade pela cultura do alho, exercendo uma expressiva influência na produtividade e qualidade dos bulbos (SENo et al., 1994). Trabalhos realizados em diversas regiões do Brasil relatam respostas do alho à adubação nitrogenada. Em trabalhos com cultivares seminobres, ganhos significativos na produtividade comercial foram obtidos com dosagens de nitrogênio de até $66 \mathrm{~kg} \mathrm{ha}^{-1}$ (Resende, 1992), $76 \mathrm{~kg}$ $\mathrm{ha}^{-1}$ (CARVAlho, 1995), $100 \mathrm{~kg} \mathrm{ha}^{-1}$ (Menezes Sobrinho et al., 1974), e $180 \mathrm{~kg} \mathrm{ha}^{-1}$ (SouzA, 1990).

O molibdênio é componente da enzima nitrato redutase, que reduz íons nitrato, possibilitando sua incorporação em compostos orgânicos, nas raízes e na parte aérea (BINNECK et al., 1999). Portanto, de acordo com FAQUin (2001), em plantas deficientes em molibdênio ocorre acúmulo de nitrato e pode haver deficiência de N. Com isso, o teor de clorofila é reduzido e o crescimento da planta é menor. Embora as plantas necessitem apenas de pequenas quantidades de molibdênio, alguns solos suprem níveis inadequados. Pequenas adições de molibdênio nessas condições podem melhorar bastante o crescimento de algumas culturas a um custo reduzido (Taiz e Zeiger, 2004).

Diante disso, o objetivo deste trabalho foi verificar a produtividade de alho vernalizado em função de doses de nitrogênio aplicadas em adubação de cobertura e de molibdênio aplicadas via foliar.

\section{MATERIAL E MÉTODOS}

O experimento foi desenvolvido em condições de campo, no município de Lavras, sul de Minas Gerais, em uma altitude média de 910 metros, a $21^{\circ} 14^{\prime}$ S e $45^{\circ} 00^{\prime} \mathrm{W}$. O clima da região, segundo a classificação de Köppen, é do tipo Cwb, caracterizado por uma estação seca entre abril e setembro e uma estação chuvosa de outubro a março. Na região a média anual de precipitação pluvial é de 1493,2 mm e temperatura de $19,3^{\circ} \mathrm{C}$ (BRASIL, 1992).

O experimento foi implantado em um solo originalmente denominado Latossolo Vermelho Distroférrico (EMBRAPA, 1999). Amostras de solo da camada de 0 a $20 \mathrm{~cm}$ foram coletadas para a realização de análises físicas e químicas. $\mathrm{Na}$ análise química do solo constataram-se os seguintes resultados: $\mathrm{pH} \mathrm{H}_{2} \mathrm{O}: 7,2 ; \mathrm{P}$ disponível (extrator Mehlich 1): $39,6 \mathrm{mg} \mathrm{dm}^{-3}$; $\mathrm{K}$ disponível: $86 \mathrm{mg} \mathrm{dm}^{-3}$; $\mathrm{Na}^{+}: 0,0 \mathrm{mg} \mathrm{dm}^{-3} ; \mathrm{Ca}^{+2}: 7,5 \mathrm{cmol}_{\mathrm{c}} \mathrm{dm}^{-3} ; \mathrm{Mg}^{+2}: 0,7 \mathrm{cmol}_{\mathrm{c}}$ $\mathrm{dm}^{-3} ; \mathrm{Al}^{+3}: 0,0 \mathrm{cmol}_{\mathrm{C}} \mathrm{dm}^{-3} ; \mathrm{H}+\mathrm{Al}^{+3}: 1,9 \mathrm{cmol}_{\mathrm{C}} \mathrm{dm}^{-3}$; SB: $8,4 \mathrm{cmol}_{\mathrm{C}} \mathrm{dm}^{-3}$; t: $8,4 \mathrm{cmol}_{\mathrm{c}} \mathrm{dm}^{-3}$; T: $10,3 \mathrm{cmol}_{\mathrm{c}} \mathrm{dm}^{-3}$; V: 81,6 \%; matéria orgânica: 4,0 dag kg ${ }^{-1}$; P-rem: 13,6 $\mathrm{mg} \mathrm{L}^{-1}$; S: $11,3 \mathrm{mg} \mathrm{dm}^{-3}$; Zn: $24,3 \mathrm{mg} \mathrm{dm}^{-3}$; Fe: 33,8 $\mathrm{mg} \mathrm{dm}^{-3}$; Mn: 76,8 $\mathrm{mg} \mathrm{dm}^{-3}$; Cu: 5,0 $\mathrm{mg} \mathrm{dm}^{-3}$; B: 0,5 $\mathrm{mg} \mathrm{dm}{ }^{-3}$; Si: $20,4 \mathrm{mg} \mathrm{dm}^{-3}$. De acordo com a análise física, o solo enquadrou-se na classe textural argilolimoso. O preparo do solo consistiu de aração seguida da preparação dos canteiros com rotoencanteiradora.

Os tratamentos foram dispostos em esquema fatorial $5 \times 4$, sendo cinco doses de nitrogênio aplicadas em cobertura $\left(60,90,120,150\right.$ e $\left.180 \mathrm{~kg} \mathrm{ha}^{-1}\right)$ e quatro doses de molibdênio $\left(0,100,200\right.$ e $\left.300 \mathrm{~g} \mathrm{ha}^{-1}\right)$ aplicadas via foliar. Adotou-se o delineamento de blocos casualizados, com três repetições. Utilizou-se o arranjo em fileiras duplas com o espaçamento entre as linhas simples de $0,12 \mathrm{~cm}$ e entre fileiras duplas de $0,38 \mathrm{~cm}$. As parcelas foram constituídas por seis linhas de plantio de 1,4 m de comprimento. A área útil da parcela foi de $1 \mathrm{~m}^{2}$, sendo composta pelas 
quatro linhas centrais e desconsiderando-se $0,2 \mathrm{~m}$ das extremidades de cada linha. A distância entre canteiros foi de $0,3 \mathrm{~m}$.

A cultivar empregada foi a Roxo Pérola de Caçador, sendo os bulbos-semente provenientes de cultura de meristemas ( $4 .^{a}$ multiplicação em campo). Estes foram submetidos ao processo de vernalização em pré-plantio, sendo colocados em câmara fria com temperatura média de $4{ }^{\circ} \mathrm{C}$, por um período de 50 dias. Os bulbilhos foram classificados em peneiras em função do tamanho, utilizando-se para plantio bulbilhos retidos na peneira 3 (malha $8 \times 17 \mathrm{~mm}$ ). O plantio foi realizado no dia 17 de abril de 2007 na densidade de 10 bulbilhos por metro linear. Os bulbilhos foram previamente tratados com solução de Iprodione visando à prevenção contra patógenos de solo.

A adubação de plantio consistiu da aplicação de $150 \mathrm{~kg} \mathrm{ha}^{-1}$ de $\mathrm{P}_{2} \mathrm{O}_{5}, 150 \mathrm{~kg} \mathrm{ha}^{-1}$ de $\mathrm{K}_{2} \mathrm{O}, 18 \mathrm{~kg} \mathrm{ha}^{-1}$ de $\mathrm{Mg}$, $3 \mathrm{~kg} \mathrm{ha}^{-1}$ de B e $3 \mathrm{~kg} \mathrm{ha}^{-1}$ de $\mathrm{Zn}$, nas formas de superfosfato simples, cloreto de potássio, sulfato de magnésio, bórax e sulfato de zinco respectivamente. Para N, em todos os tratamentos, foram aplicados 30 $\mathrm{kg} \mathrm{ha}^{-1}$ na forma de sulfato de amônio no plantio. A adubação nitrogenada de cobertura foi efetuada conforme as doses estabelecidas nos tratamentos, sendo realizada em duas parcelas, aos 20 e 90 dias após o plantio, com a distribuição, respectivamente, de $20 \%$ e $80 \%$ da dose e utilizando-se como fonte a uréia.

As doses de molibdênio foram aplicadas via foliar aos 90 dias após o plantio na forma de molibdato de sódio. A aplicação foi realizada com pulverizador costal, utilizando-se volume de calda equivalente a $350 \mathrm{~L} \mathrm{ha}^{-1}$. Para realizar a pulverização as parcelas foram isoladas com cercado plástico.

Visando à prevenção e ao controle de doenças como mancha-púrpura e ferrugem, foram realizadas pulverizações com produtos à base de Mancozeb, Tebuconazole, Tiofanato-Metílico e Oxicloreto de Cobre. O controle de pragas, como tripes e ácaros, foi efetuado mediante pulverizações com produtos à base de Deltametrina, Clorfenapir e Carbaril. A infestação por plantas daninhas foi controlada através de capinas manuais e com o uso de herbicidas à base de Linuron e Oxadiazon.

A irrigação do experimento foi realizada a cada dois dias aplicando-se lâmina de $7 \mathrm{~mm}$ por meio do sistema de aspersão convencional. Aos 65 dias após o plantio, a irrigação foi suspensa por 20 dias visando diminuir a incidência de superbrotamento (MACÊDO et al., 2006), não ocorrendo também chuvas neste período.
A colheita do experimento foi feita aos 130 dias após o plantio, na fase de senescência das plantas, quando havia em torno de quatro folhas verdes. Após a colheita, as plantas foram curadas ao sol por cinco dias. Posteriormente, as plantas foram acondicionadas em galpão onde foram curadas à sombra por 40 dias. Efetuada a cura, foi realizado o toalete dos bulbos, através do corte do pseudocaule 1 $\mathrm{cm}$ acima do bulbo e retirada de raízes e películas sujas, coletando-se posteriormente os dados de produção.

Avaliaram-se as seguintes características: produtividade total de bulbos, produtividade de bulbos comerciais, porcentagem de bulbos superbrotados, massa fresca média de bulbo comercial, número médio de bulbilhos por bulbo e massa fresca média de bulbilhos. A produtividade comercial foi composta por bulbos não superbrotados e com diâmetro transversal acima de $32 \mathrm{~mm}$, os quais foram classificados em classes de acordo com a portaria n. ${ }^{\circ}$ 242 de 17/9/1992 do MAPA: classe 3 (mais de 32 até $37 \mathrm{~mm}$ ), classe 4 (mais de 37 até $42 \mathrm{~mm}$ ), classe 5 (mais de 42 até $47 \mathrm{~mm}$ ), classe 6 (mais de 47 até 56 $\mathrm{mm})$ e classe $7(>56 \mathrm{~mm})$. Após a classificação foi determinada a porcentagem de cada classe na produtividade comercial. A massa média de bulbo foi obtida considerando apenas os bulbos classificados nas classes 7, 6 e 5. Para a determinação do número médio de bulbilhos por bulbo e massa fresca média de bulbilhos utilizou-se amostra de dez bulbos classificados nas classes 7,6 e 5, que foram debulhados para contagem e pesagem de bulbilhos. Os dados foram submetidos à análise de variância, sendo as comparações entre os tratamentos efetuadas através de análises de regressão. Para a realização da análise de variância os dados de porcentagem de bulbos comerciais por classe e de bulbos superbrotados foram transformados para arco seno $\sqrt{X / 100}$ e os dados de número de bulbilhos por bulbos para $\sqrt{x+1}$.

\section{RESULTADOS E DISCUSSÃO}

Não se observou interação entre os fatores estudados para nenhuma das características avaliadas, sendo o desempenho produtivo da cultura influenciado de maneira isolada pelas doses de nitrogênio e molibdênio aplicadas.

A produtividade total de bulbos aumentou de forma linear com o aumento da dose de nitrogênio (Figura 1). De acordo com Souza e Casali (1986), o nitrogênio exerce enorme influência sobre o número de folhas e de bulbilhos, tamanho de bulbos e produtividade do alho. Diversos trabalhos têm relatado aumento na produtividade de bulbos com a utilização de maiores doses de nitrogênio. 
Acréscimos significativos foram obtidos para doses de nitrogênio de até $120 \mathrm{~kg} \mathrm{ha}^{-1}$ (RESENDE e SOUZA, 2001a), $140 \mathrm{~kg} \mathrm{ha}^{-1}$ (RESENDE, 1997), $150 \mathrm{~kg} \mathrm{ha}^{-1}$ (YADAV, 2003) e $180 \mathrm{~kg} \mathrm{ha}^{-1}$ (SouZA, 1990). Entretanto, Costa (1992), SANtos (1980) e BiAsi et al. (1985) não constataram respostas significativas para a produção de bulbos ao estudarem doses crescentes desse nutriente.

De acordo com MagalHães (1986), a resposta à adubação nitrogenada depende do teor de matéria orgânica no solo, textura do solo e condições químicas e climáticas que afetam a dinâmica de transformação do nutriente. Além disso, nas cultivares de alho verificam-se respostas diferenciadas ao nitrogênio nas mesmas condições.

A produtividade comercial também aumentou linearmente com o acréscimo nas doses de nitrogênio avaliadas (Figura 1). Da mesma forma, Souza (1990), em trabalho com a cultivar Juréia, obteve aumento linear na produtividade de bulbos comerciais para doses de até $180 \mathrm{~kg} \mathrm{ha}^{-1}$ de N, e da dose zero para a maior dose o autor observou aumento de $3,8 \mathrm{t} \mathrm{ha}^{-1}$ na produtividade comercial de bulbos. Entretanto, Resende (1992) e CARvalho (1995) verificaram resposta quadrática da produtividade comercial em relação às doses de $\mathrm{N}$, posto que os autores registraram produtividade comercial máxima com as doses de $66 \mathrm{~kg} \mathrm{ha}^{-1}$ e 76 $\mathrm{kg} \mathrm{ha}{ }^{-1}$, respectivamente, havendo queda no rendimento em maiores dosagens. Resultado contrário ao obtido no presente trabalho foi relatado por Resende e Souza (2001a), que verificaram redução linear da produtividade comercial de bulbos da cultivar Quitéria para doses entre 40 e $120 \mathrm{~kg}$ ha ${ }^{-1}$ de nitrogênio, principalmente em função do aumento nos índices de superbrotamento em maiores dosagens.

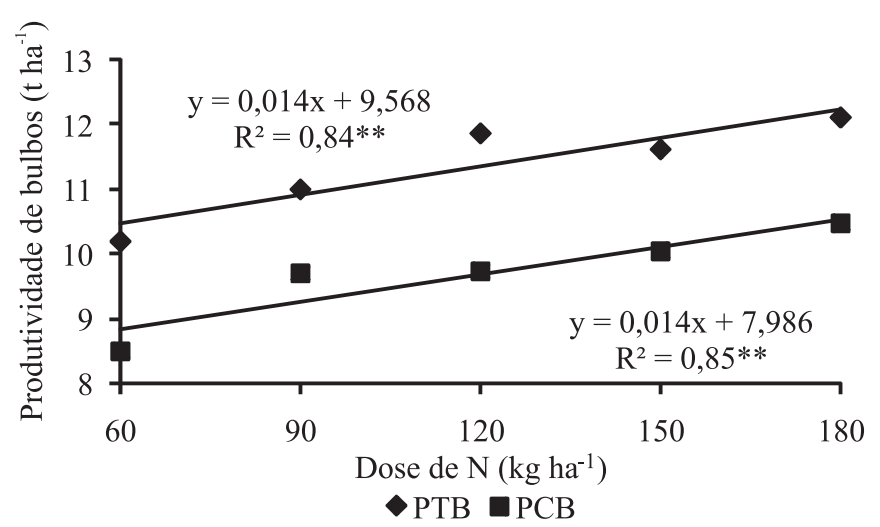

Figura 1. Produtividade total (PTB) e comercial (PCB) de bulbos de alho vernalizado em função de doses de nitrogênio aplicadas em adubação de cobertura.
Considerando-se as classes de bulbos em função do diâmetro transversal, não se verificou influência das doses de nitrogênio e molibdênio na porcentagem de bulbos das classes 7 e 3 , sendo as porcentagens médias obtidas para estas duas classes, respectivamente, de $3,8 \%$ e $20,8 \%$. Observouse incremento na porcentagem de bulbos pertencentes à classe 6 e redução na porcentagem de bulbos classe 4 com a elevação das doses de nitrogênio (Figura 2). Este aspecto possivelmente contribuiu para a obtenção de maiores produtividades de bulbos com a utilização de doses mais elevadas de nitrogênio em cobertura.

LiPINSKI e GAVIOLA (1999), em trabalho visando avaliar doses de 0,150 e $300 \mathrm{~kg} \mathrm{ha}^{-1}$ de nitrogênio, também verificaram aumento na porcentagem de bulbos de maior diâmetro com a elevação das doses de nitrogênio. Os autores observaram redução na porcentagem de bulbos com diâmetro abaixo de 45 $\mathrm{mm}$ e aumento na porcentagem de bulbos com diâmetro acima de $56 \mathrm{~mm}$ com a elevação da dose de N. Utilizando material da cultivar Gigante Roxão proveniente de cultura de tecidos, RESENDE (1997) verificou aumento linear no diâmetro dos bulbos com a elevação das doses de nitrogênio até $140 \mathrm{~kg} \mathrm{ha}^{-1}$. Com o plantio de bulbilhos oriundos de multiplicação convencional, a dose que proporcionou o maior diâmetro de bulbos foi de 119 kg ha ${ }^{-1}$. Entretanto, SENo et al. (1994) não constataram variação na porcentagem de bulbos das diferentes classes com doses de até $256 \mathrm{~kg} \mathrm{ha}^{-1}$ de N. Além de alta produtividade comercial, é interessante a obtenção de bulbos de maior diâmetro, pois alcançam melhores cotações no mercado. Em levantamento realizado pela EPAGRI (2007), em Santa Catarina em agosto de 2007, verificou-se grande diferença de preços recebidos pelos agricultores considerando-se as diferentes classes de alho. $\mathrm{O}$ preço médio recebido pela caixa de $10 \mathrm{~kg}$ de alho tipo 6 e 7 foi de $R \$ 34,00$, enquanto para as classes 5,4 e 3 o valor recebido foi $R \$ 30,00, R \$ 22,00$ e $R \$ 16,00$ respectivamente. Com relação à porcentagem de bulbos da classe 5, observou-se redução linear ( $\mathrm{y}=$ $\left.0,016 x+19,99, R^{2}=0,85^{* *}\right)$ com a elevação das doses de molibdênio. Devido ao alto $\mathrm{pH}$ registrado no solo em que foi realizado o presente trabalho, possivelmente a disponibilidade deste micronutriente também estava elevada, inibindo a resposta da cultura à sua aplicação. De acordo com Malavolta (1976), a carência deste molibdênio está associada com pH menor que 5,5. Além disso, Magalhães (1986) sugere que talvez a quantidade do elemento contido na reserva do bulbilho seja suficiente para suprir as necessidades da planta. 


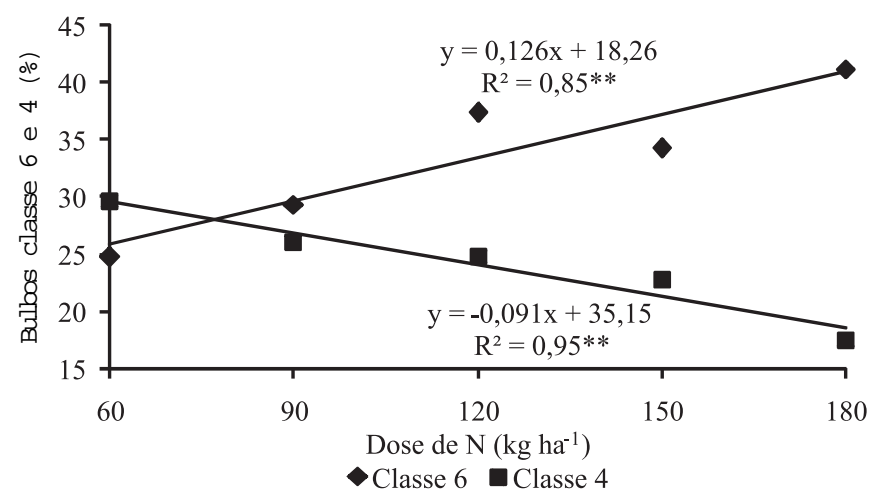

Figura 2. Porcentagem de bulbos das classes 6 e 4 de alho vernalizado em função de doses de nitrogênio aplicadas em adubação de cobertura.

Não foram constatadas diferenças entre os tratamentos com relação à incidência de superbrotamento, sendo verificada uma taxa média de $8,7 \%$, considerada relativamente baixa. O estresse hídrico a que a cultura foi submetida entre 65 e 85 dias após o plantio provavelmente minimizou os efeitos das maiores doses de $\mathrm{N}$ avaliadas no aumento da incidência desta anomalia. Esse resultado provavelmente favoreceu o acréscimo linear na produtividade comercial com a elevação da dose de nitrogênio, considerando-se que o rendimento de bulbos comerciais tende a reduzir com maiores índices de superbrotamento. Carvalho (1995) e SEno et al. (1994) também não verificaram diferenças significativas na ocorrência de superbrotamento para doses de nitrogênio de até 120 e $256 \mathrm{~kg} \mathrm{ha}^{-1}$ respectivamente. Em diversos trabalhos, porém, observou-se aumento na taxa de ocorrência desta anormalidade com maiores doses de nitrogênio, como nos realizados por RESENDE (1992), RESENDE e SOUZA (2001a), Resende e Souza (2001b) e Souza (1990). Entretanto, vale ressaltar que nesses trabalhos a irrigação não foi suspensa no início do período de bulbificação. Além disso, deve-se considerar o grau de sensibilidade das diferentes cultivares avaliadas nestes estudos ao superbrotamento. A incidência dessa anomalia está estreitamente relacionada a aplicações de doses excessivas de nitrogênio, principalmente em cobertura. Porém, nas cultivares nobres, por terem adaptação climática forçada pela vernalização para plantio em regiões menos frias que as de origem, há forte influência das variações climáticas, que podem alterar o desenvolvimento da planta e levar a respostas diferentes de ano para ano (Büll et al., 2002).

Não houve variação na massa média de bulbo em função das diferentes doses de nitrogênio e molibdênio, sendo o valor médio observado de 35,4 g. Santos (1980), Costa (1992) e Seno et al. (1994) também não verificaram diferenças significativas para esta característica com doses de até 100,120 e $256 \mathrm{~kg}$ ha $^{-1}$ de $\mathrm{N}$, respectivamente. Porém, em outros trabalhos foram verificados ganhos lineares na massa média de bulbos com a elevação das doses de $\mathrm{N}$ até $160 \mathrm{~kg} \mathrm{ha}^{-1}$ (RESENDE, 1992) e $180 \mathrm{~kg} \mathrm{ha}^{-1}$ (SOUZA, 1990). De acordo com Resende e Souza (2001a), a massa média de bulbos é característica de grande importância para a comercialização do alho, visto que os bulbos maiores recebem as melhores cotações nos mercados consumidores.

Não houve variação no número médio de bulbilhos por bulbo também com a aplicação das diferentes doses de nitrogênio, sendo o valor médio observado no experimento de 13,1. Resultado semelhante foi obtido para doses de até $160 \mathrm{~kg} \mathrm{ha}^{-1}$ (REsende e Souza, 2001b) e $256 \mathrm{~kg} \mathrm{ha}^{-1}$ (Seno et al., 1994). Todavia, Resende e Souza (2001a) observaram aumento linear no número de bulbilhos por bulbo com o incremento nas doses de nitrogênio até $120 \mathrm{~kg} \mathrm{ha}^{-1}$. O mesmo resultado foi obtido por RESENDE (1992) para doses de até $160 \mathrm{~kg} \mathrm{ha}^{-1}$. Segundo o autor, a ocorrência de superbrotamento de forma parcial, não afetando a produção comercial, pode ter contribuído para o aumento no número de bulbilhos por bulbo. O número de bulbilhos por bulbo é uma característica importante na cultura do alho. Em diversas cultivares nacionais nota-se número excessivo de bulbilhos. Por esta razão, tais cultivares possuem bulbos cuja parte central produz bulbilhos pequenos, denominados "palitos". Não há boa cotação em mercados mais exigentes para cultivares com essas características. Por outro lado, cultivares com número muito pequeno de bulbilhos por bulbo elevam muito o custo da cultura quando há necessidade de adquirir o alho-planta (SouzA, 1990).

Verificou-se resposta quadrática da massa média de bulbilho em relação às doses de nitrogênio estudadas $\left(\mathrm{y}=-0,000042 \mathrm{x}^{2}+0,010 \mathrm{x}+2,212, \mathrm{R}^{2}=\right.$ $\left.0,72^{* *}\right)$, sendo a dose $119 \mathrm{~kg} \mathrm{ha}^{-1}$ a que possibilitou a obtenção do máximo valor $(2,81 \mathrm{~g})$. SANTOS (1980) observou que a dose de $50 \mathrm{~kg} \mathrm{ha}^{-1}$ proporcionou ligeiro aumento na porcentagem de bulbilhos maiores e baixa taxa de bulbilhos menores. Com a elevação da dose de nitrogênio para $100 \mathrm{~kg} \mathrm{ha}^{-1} \mathrm{o}$ autor observou a maior porcentagem de bulbilhos menores. Entretanto, SENO et al. (1994) não verificaram efeito de doses até $256 \mathrm{~kg} \mathrm{ha}^{-1}$ na massa média de bulbilhos. De acordo com Souza (1990), cultivares que produzem cerca de 10 bulbilhos por bulbo com, normalmente, bulbilhos de bom tamanho comercial e ao mesmo tempo, não constituem fator limitante para olericultores que necessitam de aquisições freqüentes de alho para plantio. Segundo LAMMERINK (1988), os produtores devem plantar bulbilhos no mínimo, da classe 3, ou ao redor de 2,0 $\mathrm{g}$ para as cultivares de alto potencial produtivo. $\mathrm{O}$ 
autor verificou que para cada grama de aumento na massa dos bulbilhos plantados, a produção de bulbos aumentou até $1,4 \mathrm{t} \mathrm{ha}^{-1}$. Observou-se menor massa média de bulbilho nos tratamentos em que foi realizada a pulverização com molibdênio, e a resposta às diferentes doses ajustou-se ao modelo quadrático $\left(\mathrm{y}=0,000005 \mathrm{x}^{2}-0,00191 \mathrm{x}+2,856, \mathrm{R}^{2}=\right.$ $\left.0,87^{*}\right)$.

De acordo com MARSCHNER (1995), a quantidade de molibdênio requerida pelo metabolismo de plantas é menor que o da maioria dos nutrientes. Porém, este micronutriente é de grande intervalo entre a faixa de suficiência e toxidez. Em solos de Patos de Minas (MG), também não foi obtida resposta à aplicação de molibdênio na cultura do alho. Provavelmente, a cultura está entre as espécies menos sensíveis à falta deste micronutriente (Malavolta, 1976).

\section{CONCLUSÕES}

1. Em alho vernalizado, o aumento na dose de nitrogênio aplicada em adubação de cobertura até 180 $\mathrm{kg} \mathrm{ha}^{-1}$ possibilita ganhos lineares em produtividade total e comercial, além de aumento na porcentagem de bulbos classe 6 , de maior diâmetro.

2. Não houve incremento da produtividade com uso de adubação foliar com molibdênio.

\section{AGRADECIMENTOS}

Ao Conselho Nacional de Desenvolvimento Científico e Tecnológico ( CNPq) pelas bolsas concedidas e pelo financiamento do projeto. Ao programa de pós-graduação em Agronomia/Fitotecnia da Universidade Federal de Lavras (UFLA) pela oportunidade de realização do curso de Doutorado e ao Departamento de Ciência do Solo pelo auxílio na realização deste trabalho.

\section{REFERÊNCIAS}

BIASI, J.; MUELLER, S.; MACHADO, M.O.; VIZZOTTO, V.J. Cultura do alho: doses de nitrogênio e épocas de aplicação. In: CONGRESSO BRASILEIRO DE OLERICULTURA, 25., 1985, Blumenau. Horticultura Brasileira, v.3, p.61. 1985.

BINNECK, E.; BARROS, A.C.S.A.; VAHL, L.C. Peletização e aplicação de molibdênio em sementes de trevo-branco. Revista Brasileira de Sementes, v.21, p.203-207, 1999.

BRASIL. Ministério da Agricultura e Reforma Agrária. Normais Climatológicas. 1961-1990. Brasília: SPI/ EMBRAPA, 1992. 84p.
BÜLL, L.T.; BERTANI, R.M.A.; VILLAS BÔAS, R.L.; FERNANDES, D.M. Produção de bulbos e incidência de pseudoperfilhamento na cultura do alho vernalizado em função de adubações potássicas e nitrogenadas. Bragantia, v.61, p.247$255,2002$.

CARVALHO, L.G. Efeitos de diferentes lâminas de água e doses de nitrogênio e potássio na cultura do alho (Allium sativum L.) cv. Gigante Lavínia. 1995. 72p. Dissertação (Mestrado em Engenharia Agrícola) - Universidade Federal de Lavras, Lavras, MG.

COSTA, T.M. Efeitos de diferentes lâminas de água e doses de nitrogênio sobre a cultura do alho (Allium sativum $\mathbf{L}$.) $\mathbf{c v}$. Juréia. 1992. 80p. Dissertação (Mestrado em Fitotecnia) Universidade Federal de Lavras, Lavras, MG.

EMBRAPA. Centro Nacional de Pesquisa de Solos. Sistema brasileiro de classificação de solos. Rio de Janeiro: Embrapa solos, 1999. 412p.

EPAGRI. Centro de Socioeconomia e planejamento Agrícola. Preços médios mensais recebidos pelos agricultores. Florianópolis, 2007. Disponível em: < http:// cepa.epagri.sc.gov.br/>. Acesso em 6 dez. 2007.

FAQUIN, V. Nutrição Mineral de Plantas. Lavras: UFLA, 2001. 182p. (UFLA. Textos Acadêmicos)

FILGUEIRA, F.A.R. Novo manual de olericultura: agrotecnologia moderna na produção e comercialização de hortaliças. Viçosa: UFV, 2003. 402p.

LAMMERINK, J. Better garlic yields through selection and seed clove grading. New Zealand Commercial Grower, v.43, p.16-17, 1988.

LIPINSKI, V.M.; GAVIOLA, S. Fuentes y dosis de nitrógeno em fertigación de ajo cv. Fuego-INTA. Horticultura Argentina, v.18, p.28-32, 1999.

MACÊDO, F.S.; SOUZA, R.J.; PEREIRA, G.M. Controle de superbrotamento e produtividade de alho vernalizado sob estresse hídrico. Pesquisa Agropecuária Brasileira, v.41, p.629635, abr. 2006.

MAGALHÃES, J.R.de. Nutrição mineral do alho. Informe Agropecuário, v.12, p.20-30, 1986.

MALAVOLTA, E. Manual de química agrícola: nutrição mineral de plantas e fertilidade do solo. São Paulo: Agronômica Ceres, 1976. 528p.

MARSCHNER, H. Mineral nutrition of higher plants. 2.ed. London: Academic Press, 1995. 889p.

MENEZES SOBRINHO, J.A.; NOVAIS, R.F.; SANTOS, H.L.; SANS, L.M.A. Efeito da aplicação de doses de nitrogênio e da cobertura morta sobre a produção de três cultivares de alho. Revista Ceres, v.21, p.458-469, 1974.

RESENDE, F.V. Crescimento, absorção de nutrientes, resposta à adubação nitrogenada e qualidade de bulbos de alho proveniente de cultura de tecidos. 1997.139p. Tese (Doutorado em Fitotecnia) - Universidade Federal de Lavras, Lavras, MG. 
RESENDE, F.V.; DUSI, A.N.; MELO, W.F.de. Recomendações básicas para a produção de alho em pequenas propriedades. Brasília: EMBRAPA-CNPH, 2004. 12p. (EMBRAPA-CNPH. Comunicado Técnico, 22)

RESENDE, G.M. Influência do nitrogênio e paclobutrazol na cultura do alho (Allium sativum L.) cv. Quitéria. 1992. 107p. Dissertação (Mestrado em Fitotecnia) - Universidade Federal de Lavras, Lavras, MG.

RESENDE, G.M.; SOUZA, R.J. Doses e épocas de aplicação de nitrogênio sobre a produtividade e características comerciais de alho. Horticultura Brasileira, v.19, p.126-129, 2001a.

RESENDE, G.M.; SOUZA, R.J. Efeitos de tipos de bulbos e adubação nitrogenada sobre a produtividade e características comerciais do alho cv. Quitéria. Horticultura Brasileira, v.19, p.188-191, 2001b.

SANTOS, M.L.B. Efeitos de fontes e níveis de nitrogênio sobre o desenvolvimento e produção de dois cultivares de alho (Allium sativum L.). 1980. 74p. Dissertação (Mestrado em Fitotecnia) - Universidade Federal de Lavras, Lavras, MG.

SENO, S.; FERNANDES, F.M.; SASAKI, J.L.S. Influência de doses e épocas de aplicação de nitrogênio na cultura do alho (Allium satioum L.) cv. Roxo Pérola de Caçador, na região de Ilha Solteira-SP. Cultura Agronômica, v.3, p.9-20, 1994.

SOUZA, R.J.de. Influência do nitrogênio, potássio, cycocel e paclobutrazol na cultura do alho (Allium sativum L.). 1990. 143p. Tese (Doutorado em Fitotecnia) - Universidade Federal de Viçosa, Viçosa, MG.

SOUZA, R.J.; CASALI, V.W.D. Pseudoperfilhamento - uma anormalidade genético-fisiológica em alho. Informe Agropecuário, v.12, p.36-41, out. 1986.

TAIZ, L.; ZEIGER, E. Fisiologia vegetal. Porto Alegre: Artmed, 2004. 719p.

YADAV, P.K. Effect of nitrogen and potassium on growth and yield of garlic (Allium sativum) in Western Rajasthan. Haryana Journal of Horticultural Sciences, v.32, p.290-291, 2003. 